\title{
Plant invasions in New Zealand: global lessons in prevention, eradication and control
}

\author{
Philip E. Hulme
}

Received: 10 December 2019/ Accepted: 6 February 2020

(C) The Author(s) 2022, corrected publication 2020

\begin{abstract}
The number of non-native plant species established outside of cultivation in the New Zealand archipelago is higher than for any other islands worldwide. Faced with this scale of plant invasions, there has been considerable investment in the scientific and operational aspects of prevention, eradication and control. As a result, New Zealand is ideally placed to illustrate the many challenges that plant invasions present worldwide as well as the possible solutions. New Zealand has been at the forefront of biosecurity policy developments to tackle plant invasions being one of the first countries to: (a) implement national legislation to address the management of nonnative plants; (b) establish a national permitted list (white-list) for plant imports; and (c) introduce bans on the sale, distribution, or propagation of non-native plant species. However, these preventative measure are only effective where there are also adequate border inspection regimes, compliance monitoring of the horticulture industry, and surveillance of internet trade. While New Zealand has successfully eradicated several non-native plant species from its territory, the small number of successes reflects the short-term, local and often uncoordinated efforts to manage nonnative plants rather than national programmes backed by legislation and financed over several decades. New
\end{abstract}

P. E. Hulme ( $\square)$

The Bio-Protection Research Centre, Lincoln University, PO Box 85084, Canterbury, New Zealand

e-mail: philip.hulme@lincoln.ac.nz
Zealand supports a world-leading biological control programme, but this has led to sustained, large-scale control for only a handful of species. In natural areas, most management attempts using mechanical or herbicide treatments have failed to achieve control and there has been a progressive reduction in the area, and frequency of these programmes over time. This is illustrative of the challenges facing those responsible for managing non-native plants in any region of the world. A general insight is that a shift in mindset is required that overcomes significant cognitive biases that include succumbing to the pressure to always intervene, underestimating the non-linear trajectories of invasions, failing to articulate the values at stake, and underestimating the time programmes require to succeed. Important lessons of global relevance include the need for managers to: (a) recognise when and where sleeper weeds are likely to become a national issue, especially as a result of climate change; (b) quantify impacts on those values that stakeholders most cherish rather than those that are easy to measure; (c) provide accurate estimates of the potential future extent of the invasion in the absence of management; and (d) identify clear indicators of successful progress over the course of a long-term management programme.

Keywords Aquatic - Climate change $\cdot$ Lag-phase · Pathway $\cdot$ Propagule pressure $\cdot$ Restoration $\cdot$ Weed 


\section{Introduction}

The scale and consequence of biological invasions in New Zealand represent an object lesson as to why the introduction of species across biogeographic boundaries should never be considered lightly. Ever since the initial settlement by Polynesians in the late $13^{\text {th }}$ century, introduced plants have played a significant role in the economy and culture of New Zealand. However, while Polynesian settlers introduced a handful of crops and their associated weed species to New Zealand (Leach 2005), the arrival of European colonists in the 1800s brought about a dramatic shift in the rate and number of plant species introduced (Williams and Cameron 2006). Within 200 years of European settlement, the number of non-native plant species established outside of cultivation in the New Zealand archipelago had become higher than any other islands worldwide (Fig. 1). Indeed, today approximately half of all vascular plants found in the wild in New Zealand are non-native (Diez et al. 2009).

Nearly all types of native plant communities, including hundreds of thousands of hectares of conservation land, have been invaded by non-native plant species, and they now dominate in many lowland forests, coastal habitats, wetlands, shrublands and tussock grasslands, as well as many lakes and lowland rivers (Aikio et al. 2012; Williams 1997). Native plant communities appear particularly vulnerable to the impacts of non-native plant species (Hejda 2013; Nielsen et al. 2017). Plant invasions pose a threat to more than half of New Zealand's critically endangered ecosystems (Wiser et al. 2013). They are also the main hazard to one-third of all New Zealand nationally threatened plant species (Table 1) and are estimated to have degraded the conservation estate in terms of loss of native biodiversity equivalent to more than US \$1 billion (Hulme 2017b). A similar financial cost is met by the agriculture and forestry sectors through reductions in crop yields and management expenditure arising from the impacts of non-native plants (Saunders et al. 2017). While such impacts are not unique to New Zealand, arguably the scale and speed of the transformation of the landscape has no equal anywhere in the world. As a result, New Zealand is ideally suited not only to illustrate the many challenges that plant invasions present worldwide but also the possible solutions.

\section{Historical lessons for the future}

As is typical for most regions of the world (Seebens et al. 2017), the number of naturalised non-native plants in New Zealand has exhibited a progressive increase over time since European colonisation (Fig. 2). However, the temporal rate at which nonnative plants have naturalised in New Zealand is
Fig. 1 Although a positive relationship exists between island area $(\log$ transformed) and the number of naturalised nonnative plant species

$\left(\mathrm{F}_{(1,360)}=145.41\right.$,

$\left.\mathrm{R}^{2}=0.288, P<0.001\right)$, relative to their land area, the North (black triangle) and South (back circle) islands of New Zealand harbour more naturalised non-native plant species than almost any other island worldwide. Data from Pysek et al. (2017)

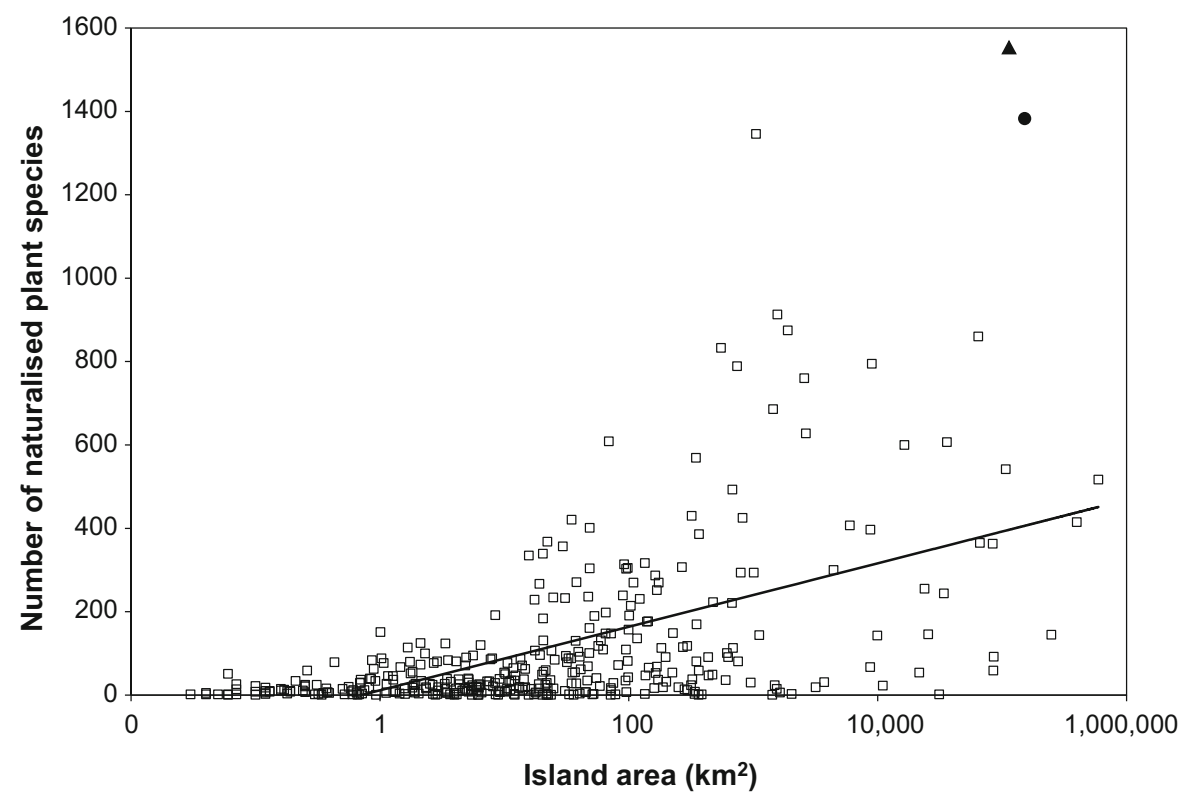




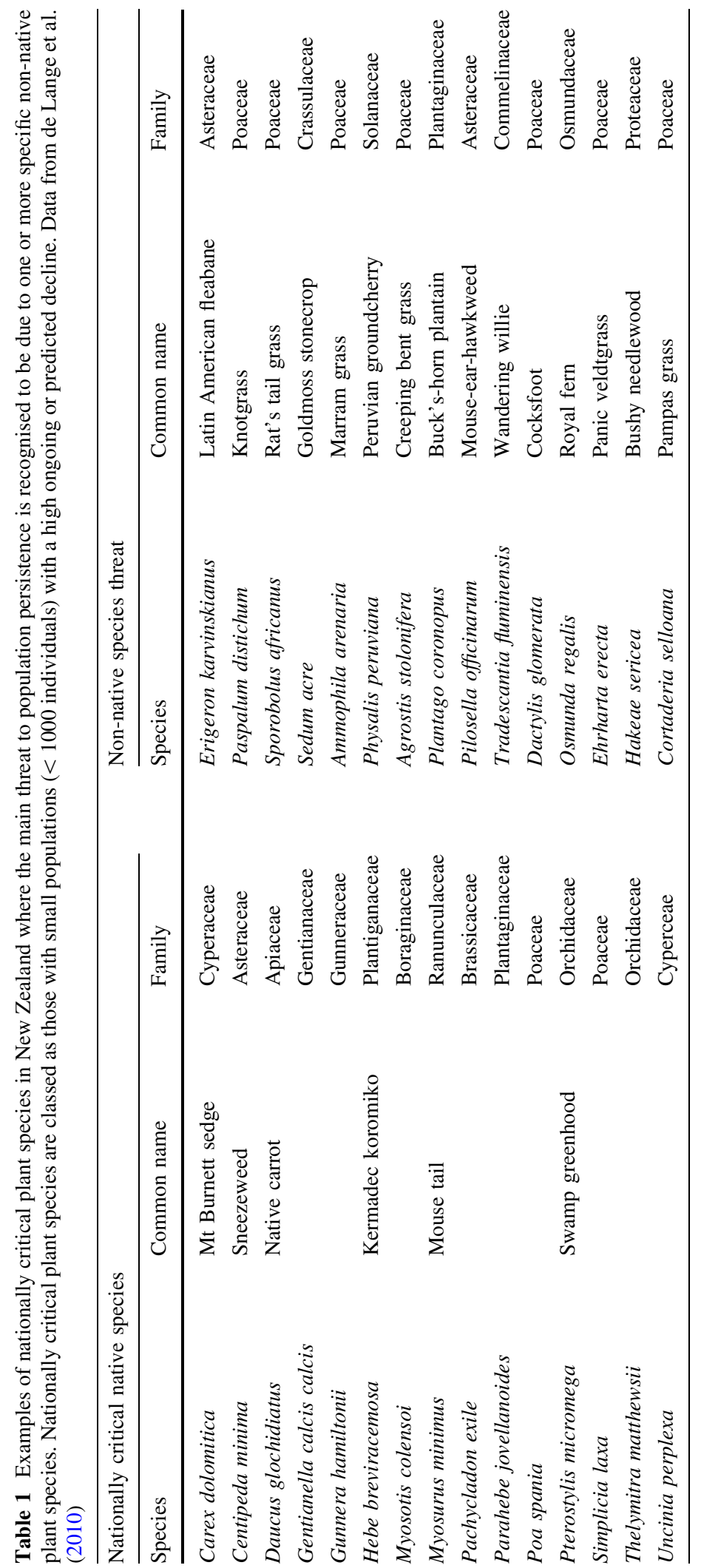


Fig. 2 Temporal trend in the total number of naturalised non-native plant species recorded in New Zealand and the contribution to that total from species introduced intentionally for ornamental horticulture, agriculture (including forestry) or unintentionally introduced. Data from Gatehouse (2008)

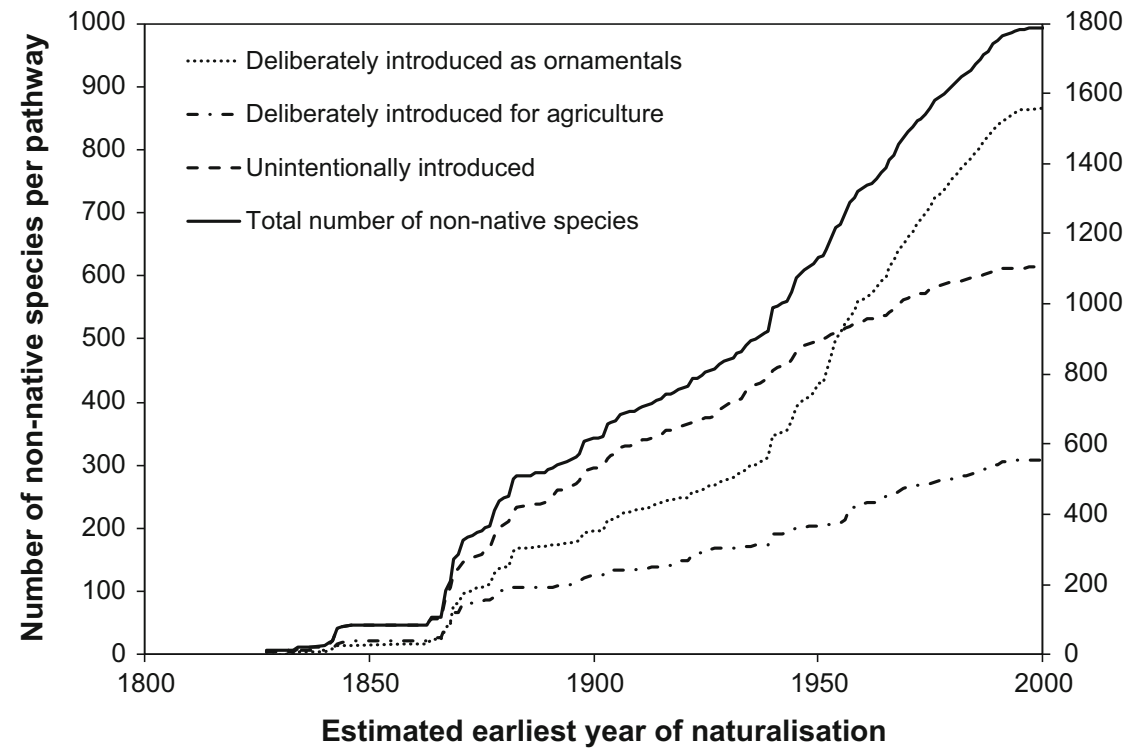

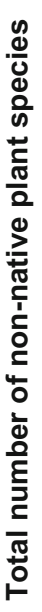

several times higher than in other regions (e.g. Ansong et al. 2019; Barina et al. 2014; Camarda et al. 2016; Pysek et al. 2012). Nevertheless, there are at least two important caveats when examining such trends. First, since such records are often based on vouchered herbarium specimens, they will often underestimate the date of first naturalisation by a decade or more. For example, the first published botanical record in New Zealand for Scotch (Cirsium vulgare) and Californian (C. arvense) thistles is 1867 and 1878 respectively (Webb et al. 1988). Yet, there were already provincial government ordnances aimed to control these thistles in the 1850s (Worsley 1999) indicating these two species were already widespread and must have naturalised many years earlier. Second, most historical checklists have significantly underestimated the size of the non-native flora. Based on contemporary estimates (Fig. 2), major compilations of the naturalised flora by Thomson (1922) and Allan (1940) underestimated the number of non-native species by as much as $35 \%$ and $55 \%$ respectively! These caveats suggest that even today, with all the benefits of citizen science and digital herbarium collection, numbers of naturalised non-native plants are likely to be underestimated and that any perceived tailing off in naturalisation rates in recent times may likely reflect artefacts arising from data compilation rather than success of policy interventions.

Despite these caveats, historical records do point to several general trends in terms of the source of non- native plants in New Zealand. At least four distinct phases can be discerned from the temporal trends (Fig. 2): a period of limited naturalisation prior to 1850, a rapid increase in non-native plant species between 1850 and 1900; a shallower rate of increase up to 1940; followed by an accelerated rate up to 2000. Many of the earliest records are from non-native plants unintentionally introduced as contaminants of commodities such as grain or in soil attached to equipment imported by whalers and early settlers (e.g. Plantago major, Rumex crispus) and this pathway accounts for most introductions up until 1950 (Fig. 2). Some of the earliest cultivated species to become naturalised in New Zealand prior to 1840 (e.g. Brassica olearacea, Avena sativa, Raphanus sativa), were first introduced by Captain Cook in 1773 and were widely cultivated by early settlers, whalers and Māori (Thomson 1922). The first colonial home gardens largely focused on food crops, but some of the earliest cultivated ornamentals had become naturalised by 1840 (e.g. Lobularia maritima) while others only naturalised up to a century after their initial introduction (e.g. Dianthus barbatus, Antirrhinum majus). It should be noted that many ornamental plants, such as a numerous delphinium cultivars and hybrids, have been widely cultivated in gardens or over 175 years and have not yet become naturalised.

In 1840, there were approximately 2000 Europeans living in New Zealand but by 1900, through both immigration and high fertility rates, the colonial 
population had boomed to 770,000 individuals (Easton 2011). In the wake of this major demographic trend, numbers of naturalised non-native plant species also increased by a similar order of magnitude (Fig. 2). This was true of all pathways but especially unintentional introductions (e.g. Conyza bonariensis, Jacobaea vulgaris) as a result of the increased flux of people and goods into New Zealand. After 1840, the successful intentional introduction of plants to New Zealand was boosted by the use of Wardian cases and improved methods of seed storage during the long sea voyages (Dawson 2010). Furthermore, the 1860s saw the establishment of the first acclimatisation societies in New Zealand that set about to enrich the flora with introduced plant species (Williams and West 2000). As more non-native plants were introduced intentionally, so more were likely to escape from gardens (e.g. Agave americana, Zantedeschia aethiopica) and agricultural fields (e.g. Humulus lupus, Vitis vinifera). Awareness of the problem of non-native plants also increased through regional legislation to control noxious weeds (Worsley 1999) yet while there was general consensus that non-native plants were a significant problem in anthropogenic landscapes, there was considerable debate as to whether they also posed a threat to the native flora (Cockayne 1910; Kirk 1895). There was also a view at the turn of the century that "probably all the worst weeds of the earth have already arrived" (Cockayne 1910) which may explain why there were few formal border controls on the material being brought into New Zealand before 1900 .

The Noxious Weed Act 1900 was the first legislation anywhere in the world to address the management of non-native plants (Worsley 1999), with similar Acts only being passed in Australia in 1916, Ireland 1936, United Kingdom 1959, and USA 1974. However, border controls in the form of a seed inspection laboratory were only established in 1910 (Williams et al. 2010), several decades after most European countries and the USA. In addition, the screening of non-native plant seeds was largely restricted to taxa already established in New Zealand. Thus, not surprisingly, there appears to be no discernible change in the rate of establishment of unintentionally introduced species following the opening of the New Zealand seed inspection laboratory (Fig. 2). In contrast, this period saw a dramatic rise in the naturalisation of ornamental plants. This probably reflects a progressive shift from Victorian gardens with their lawns, flowerbeds and vegetable plots to Edwardian cottage gardens with their mixed borders of shrubs, climbers, bulbs and annuals and then later in the 1920s and 1930s more aesthetic gardens where ornamental aspects, including ponds, became a strong component (Bradbury 1995). In addition, the first state house was built in 1937, and by 1940 as many as 5000 state houses were being built each year ensuring every family, irrespective of income, could have a garden (Dawson 2010). Thus by 1950 , the propagule pressure from ornamental plantings in suburban gardens was probably higher than at any previous time and coincided with the dramatic increase in ornamental plant naturalisations (Fig. 2). From this date onwards, escapes from gardens and amenity plantings became the major pathway for new naturalisations of non-native plants. Nevertheless, there still remained considerable debate among scientists as to the extent non-native plants may lead to the replacement of native species in the absence of anthropogenic pressures (Allan 1936; Cockayne et al. 1932). Legislation under the Noxious Weeds Act was regularly amended through the twentieth century (becoming the Noxious Plants Act in 1978) to better manage established non-native plants and their propagation (Worsley 1999) while the Plants Act 1970 placed regulations on non-native plant imports including a ban on 132 aquatic taxa (Champion 2018). Yet, despite this legislation, at the close of the millennium, it was estimated that each year as many as 14 new plant species were becoming naturalised in New Zealand (Williams and Cameron 2006).

Faced with the scale of the plant invasion problem, the New Zealand government, non-governmental organisations, industry, general public and research organisations have invested heavily in both the scientific and operational aspects of prevention, eradication and control of non-native plants. The following sections examine the role of science in supporting these management and policy interventions, identify the reasons for success as well as failure in curtailing plant invasions and point to potential ways forward that are relevant not just to New Zealand but to all other parts of the globe.

\section{Prevention: red flags for white lists}

The increasing awareness of the need to manage biological invasions more effectively in New Zealand 
led to the Biosecurity Act 1993 and the Hazardous Substances \& New Organisms Act 1996 (HSNO Act) to address unintentional and intentional introduction pathways respectively (Williams and West 2000). This new legislative framework was a major departure from previous approaches addressing non-native plants since rather than being based on a prohibited list (black-list), it took the innovative step of developing a national permitted list (white-list) for the first time anywhere in the world. The white-list takes the form of the Plants Biosecurity Index, an official database of all plant species (both native and nonnative) thought to have been cultivated or established outside of cultivation prior to $29^{\text {th }}$ July 1998 . The major effort to compile a list of all native and nonnative plants in New Zealand resulted in a catalogue of approximately 27,000 vascular plant species in the Plants Biosecurity Index. If a species is not already prohibited and is listed in the Plants Biosecurity Index then it can be imported on condition that all necessary phytosanitary regulations are met. A species not on the Index will be treated as a new species and be required to undergo a detailed risk assessment undertaken by the Environmental Protection Authority to address the potential effects on the environment, human health, society, Māori culture and traditions, and the market economy. A further risk assessment undertaken by the Ministry for Primary Industries may also be necessary to ensure compliance with import health standards. The costs of these risk assessments are borne by the applicant and can be sizeable (Hulme et al. 2018). White-lists are viewed as pivotal tools in the prevention of biological invasions globally (Burgiel and Perrault 2011), yet despite the ground-breaking nature of the New Zealand legislation, the implementation of a white-list approach has not been without its problems.

The horticulture industry in New Zealand has been particularly critical of the white-list approach. Their view is that the importation of non-native plant species to New Zealand is a complex, time consuming and costly process that is a significant barrier to innovation in the horticulture industry (Hulme et al. 2018). Furthermore, the Plants Biosecurity Index only lists two-thirds of non-native plant taxa thought to be present in New Zealand. For example, a survey of aquarium plants for sale highlighted that at least $27 \%$ of the non-native species available within the aquatic plant trade were not previously recorded as present in
New Zealand (Champion and Clayton 2001). Thus prospective importers spend considerable effort providing evidence (e.g. import documents, sales or exhibition catalogues, published books and scientific papers) to import non-native plants known to be present in New Zealand prior to 29th July 1998 but not listed in the Plants Biosecurity Index (Douglas 2005). In addition, the Plants Biosecurity Index is not seen as fit for purpose in supporting import applications since it does not include: (a) non-vascular plants; (b) synonyms for most species; (c) taxonomic information or plant name authorities; or (d) species that have naturalised since 1998 with no record of presence before 29 July 1998 (Dickson 2009). An effective white-list should fulfil dual goals: support regulators in preventing the introduction of potentially invasive non-native species, but also aid importers to make successful applications for the introduction of low risk species. At present, the Plants Biosecurity Index achieves the first goal but not the second. To achieve the second would require the Plants Biosecurity Index to be a much more dynamic document, supported by ongoing taxonomic work to identify what plant species are or have been grown in New Zealand as well as greater clarity on nomenclature and the risk status of cultivars and varieties.

The view that the white-list approach is a barrier to innovation in the horticulture industry has led to attempts to circumvent the legislation through illegal imports. One result was that, during the early period of legislation, there were considerable interceptions of undeclared plant material at the New Zealand border, with as many 5800 seizures of bulbs and live plants in 2001 (Biosecurity Council 2003). The subsequent introduction of instant fines for possession of undeclared plant material, steeper penalties for evidence of deliberate smuggling, more effective inspections of international travellers using detector dogs and X-ray machines as well as comprehensive screening of all incoming international mail have led to a marked decline in seizures. Thus, the effectiveness of a whitelist in preventing the introduction of high-risk plant material is only as good as the border inspection regime that enforces the legislation. Nevertheless, while the white-list approach has been effective in reducing the rate of deliberate imports of new plant species into New Zealand, even today there are regular reports of seizures at the New Zealand border of 
smuggled seeds and plants destined for private or commercial propagation.

\section{Prevention: blacklists for green fingers}

A major future source of non-native plant species not adequately addressed by pre-border preventative approaches is the plant taxa already in New Zealand currently grown in gardens. An unknown number of species in gardens may pose a potentially significant risk to the natural environment. With recent tightening of the border and risk assessment of new plant species, deliberate introductions of potentially invasive plants to New Zealand have declined to historically low levels. While unintentional introduction of new plant species continues to occur as contaminants of grain (e.g. Alopecurus myosuroides, Abutilon theophrasti) or in other horticultural commodities such as coco peat (James et al. 2012), future plant naturalisations are expected to arise from garden escapes. There are no accurate estimates of the numbers of plant species in cultivation in gardens, although figures of over 30,000 taxa are frequently cited (Williams and Cameron 2006). Although most plants cultivated in gardens are expected to pose a low risk of naturalisation, there is strong evidence that horticultural selection can significantly increase the risk of a species naturalising and becoming invasive (Hulme 2011). Consistent with this view is that compared to their general representation in the naturalised flora $(48.4 \%)$, plant species introduced through the ornamental plant pathway are overrepresented (58.4\%) among plants listed as environmental weeds (i.e. invasive non-native plant species sensu Howell (2008)) in New Zealand $\left(\chi^{2}=15.20, d f\right.$ $1 P<0.001)$. Thus, the management of garden escapes is critical to reducing the risk of plant invasions. Such management will need to address both ornamental species already known to have become locally naturalised as well as species that have yet to escape but have the potential to naturalise in the future. While it is estimated that some nonnative plant species in New Zealand have taken between 40 and 100 years from when they first become locally naturalised to when they began to spread widely across the country (Aikio et al. 2010b), the temporal lag between an ornamental plant entering the horticulture market and subsequently jumping the garden fence to become naturalised is unknown. If this lag-time is of the order of several decades then, given the increase in ornamental plant introductions to New Zealand since the 1950s, this would imply a large reservoir of potentially invasive ornamental species currently cultivated in gardens.

The Noxious Weeds Act 1950 established the first legislation anywhere in the world to ban the propagation, sowing or sale of non-native plants. The species listed included several popular ornamentals including Eichhornia crassipes, Moraea collina, Hypericum androseamum, and Lantana camara. While subsequent amendments to the legislation extended the list of banned species in an incremental manner, it was not until 2001 that a formal arrangement was launched to specifically target the risks from garden escapes. The National Plant Pest Accord (NPPA) is a memorandum of understanding between the ornamental nursery industry and both national and local government that established a mechanism to ban non-native plant species from sale, distribution, or propagation. These prohibitions are undertaken under the Biosecurity Act 1993 and compliance is monitored both through the inspection of production, wholesale, and retail nurseries as well as surveillance of internet trading. However, the NPPA does not oblige landholders to manage naturalised populations of any species listed. The NPPA listed 92 species in 2001 and included several species covered under previous Noxious Weeds Acts and a further 60 additional species had been added to the list by 2018 . To date, no nation has excluded so many ornamental non-native species from the horticulture market and the fact that this has occurred with the full support of the nursery industry highlights that there are important lessons regarding the process relevant to other countries aiming for similar sales bans (Hulme et al. 2018).

The process of listing species on the NPPA involves a candidate list of plant species that are currently sold or have the potential to be sold through the nursery trade being drawn up and subsequently screened in relation to: (a) the risk species pose to the environment, agriculture, or human health; (b) the value of the species to the horticulture and other industries; and (c) the effectiveness of listing a species on its further introduction or spread (Newfield and Champion 2010). While there is little doubt that the species so far listed have the potential to significantly impact upon biodiversity (especially native plant diversity), agriculture or human health (Fig. 3), the NPPA list 


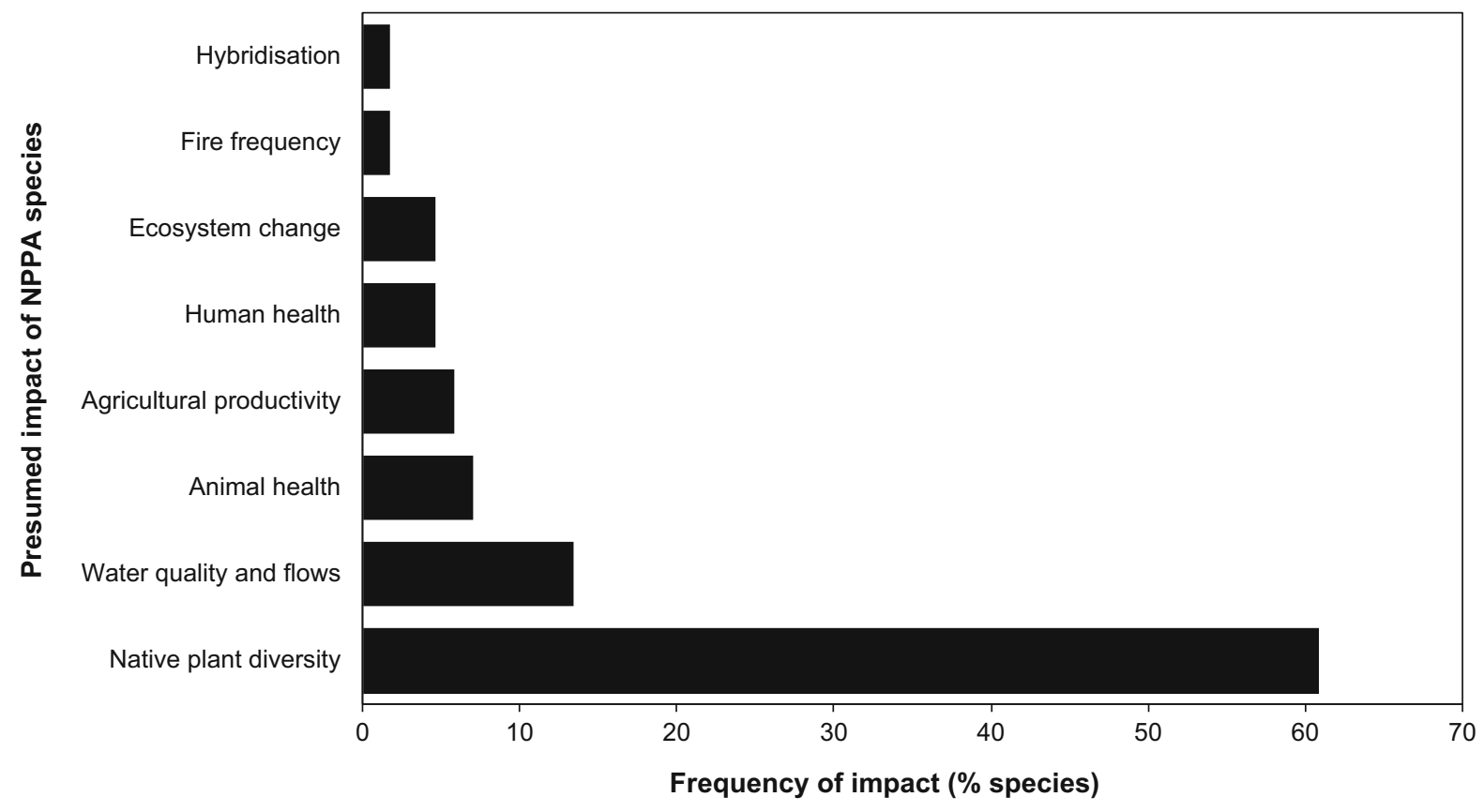

Fig. 3 The frequency with which impacts on different ecosystem services have been recorded for 152 plant species listed on the New Zealand National Plant Pest Accord. A single species may have more than one impact. Data from NPPA (2012)

includes only $37 \%$ of the environmental weeds (i.e. invasive non-native plants) listed by Howell (2008) that have a known ornamental origin. This relatively low representation of environmental weeds in the NPPA is partly attributable to the fact that many species have not been listed because of their high economic value to the horticulture industry (e.g. Agapanthus praecox, Trachycarpus fortunei, Pennisetum clandestinum). Achieving consensus regarding the banning of economically valuable species will remain a challenge, especially given the strict and costly process for importing new species into New Zealand. One future possibility is for the NPPA to consider the risks posed by species yet to be introduced to New Zealand but for which there is demand within the domestic horticulture industry. This could be done on a quid pro quo basis such that for every species banned from sale, the NPPA would assess a species not yet present in New Zealand on behalf of the industry. Such risk assessments would support applications for import of new species under the HSNO Act 1996 which could be fast-tracked at a lower cost to the industry.

How effective is banning species from sale, propagation and distribution in preventing the introduction and spread of garden escapes? The species currently listed in the NPPA range from species that have never been recorded as naturalised to widespread species found across the entire country (Fig. 4). Almost one quarter of species listed by the NPPA are found in one or fewer regions and it might be expected for these species that sales bans may be an effective means of reducing the likelihood of further introductions across the country. However, nearly one-third of species are found across at least half of the regions and thus may be sufficiently widespread that a sales ban, while certainly useful in limiting one source of introduction, may be insufficient on its own to limit further spread. Three issues will prevent the effectiveness of sales bans on the spread of these species. First, there remains a risk of non-compliance by horticultural nurseries, since nurseries have still been found to market species that have been banned for over a decade (Waikato Regional Council 2019). Second, if the species are sufficiently widely naturalised then natural dispersal from wild populations (e.g. through birds, wind or water), rather than horticultural sales, will often drive rates of spread. Third, there is a high likelihood of a large pool of banned plants still under cultivation in domestic gardens that also represents a 


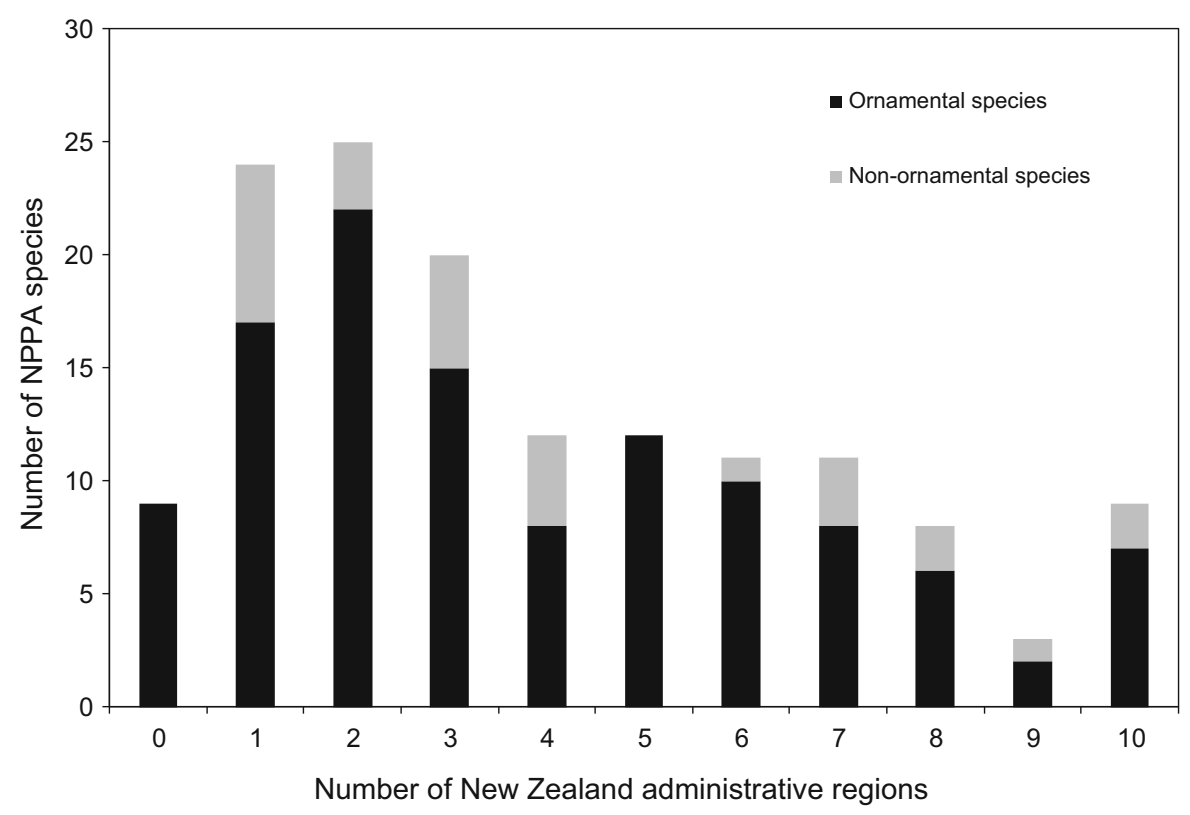

Fig. 4 Number of administrative regions (maximum of ten) in New Zealand in which ornamental and non-ornamental species listed in the National Plant Pest Accord are recorded. Data from Gatehouse (2008)

significant source of material for further introductions. The NPPA does not require homeowners to remove listed species from their gardens and indeed such a requirement could lead to greater rates of spread should members of the public dump garden refuse illegally.

While the banning of species from sale is a valuable approach in preventing the naturalisation and spread of non-native plants, it is clearly most effective for species that have only limited value to the horticulture industry and either have yet to jump the garden fence or are still quite localised in their distribution. Schemes such as the NPPA are unlikely to have much impact on preventing the escape of widely cultivated species, especially if they are popular with gardeners and thus fetch a price premium. A complimentary approach to sales bans would be to increase awareness among the gardening public about invasive non-native plants so that they can make informed choices in their purchases (and so reduce the market demand for ornamental environmental weeds) and responsibly remove such plants from their gardens. The limited evidence to date suggests this will be a significant challenge. In an analysis of the effectiveness of a brochure about the problems created by non-native plants escaping from domestic gardens in New Zealand, it was found that the brochure, by itself, did not increase the level of knowledge exhibited by recipients nor their ability to identify weeds, furthermore it did not alter the attitude of individuals who disagreed that garden plants might become invasive or that plants which escape gardens should be considered as pests (Fraser 2002). This suggests that advice at the point of sale, such as labelling species as low risk (green label), intermediate risk (amber label) or high risk (red label) might be a more effective approach (Hulme et al. 2018).

\section{Eradication: planning for the long-term}

Where policies and practices are insufficient to prevent the naturalisation of non-native plants, eradication is the next line of defence. Eradication is the complete and permanent removal of all wild populations of a species from a specific area by means of a time-limited campaign (Robertson et al. 2017). Compared to animals, non-native plants appear particularly difficult to eradicate, especially if they possess a longlived seedbank (Panetta 2015). However, similarly to non-native vertebrate and invertebrate eradications, most examples of successful outcomes are found on islands (Glen et al. 2013). In general, the likelihood of successful eradication is a function of the size, number 
and accessibility of non-native plant infestations, the detectability, persistence and dispersal potential of the target species, and the effectiveness of management methods (Panetta and Timmins 2004). Arguably the first national campaign to eradicate a non-native plant in New Zealand targeted Nassella trichotoma under specific legislation, the Nassella Tussock Act 1946, but the goal was deemed no longer feasible after 65 years of sustained management had failed to eliminate the species (Bourdot and Saville 2016). Nevertheless, to date at least eleven non-native plants have been actively eradicated from the entire New Zealand territory: Acroptilon repens, Butomus umbellatus, Chondrilla juncea, Eichhornia paniculata, Menyanthes trifoliata, Nymphoides peltata, Onopordum tauricum, Pistia stratiotes, Potamogeton perfoliatus, Typha latifolia and Zizania palustris (Champion 2018; Howell 2008; Hulme 2017b). All these species were only ever found in one or a few locations and most were contained within discrete wetland habitats that constrained their spread (Webb et al. 1988). In addition, a further ten non-native plant species have been eradicated from uninhabited islands (Campbell, Raoul, Hen and Chickens, Poor Knights) administered by New Zealand (Glen et al. 2013). Nevertheless, while New Zealand can take credit in being responsible for almost one quarter of all known non-native plant eradications from islands (Glen et al. 2013), this is a drop in the ocean in terms of the scale of plant invasions in the country.

Despite a long history of efforts to manage nonnative plants, the small number of successful eradications likely reflects the short-term, local and often uncoordinated efforts to manage non-native plants. Consequently, in 2006 the Ministry for Primary Industries (formerly the Ministry of Agriculture and Forestry) established the National Interest Pest Response Programme (NIPR) to coordinate the complete eradication of a eight non-native plant species from New Zealand that had previously been the target of piecemeal and uncoordinated activity and that were chosen with regard to the likelihood of success and the cost-benefit of eradication (Hulme 2017b). Three NIPR species listed in the Noxious Weed Act 1950: Moraea flaccida, Sorghum halepense and E. crassipes, have been the target of eradication efforts for over 70 years. They therefore provide outstanding case studies as to the challenges of non-native plant eradication, even where there is a commitment to a long-term programme of surveillance and eradication (Fig. 5).

The undoubted success story of the NIPR programme has been $S$. halepense, an agricultural weed accidentally introduced in contaminated grain, which to all intents and purposes has been eradicated with no new populations detected for over 8 years since 2011 (Fig. 5a). However, because $S$. halepense is a regulated weed species under international trade, a change in country status to "eradicated" is still pending a formal audit by the International Plant Protection Convention. In contrast, notwithstanding the considerable success in reducing the number of populations from several hundred in the 1980s to a low of 19 sites in 2001, eradication of M. flaccida, a garden escape that is poisonous to livestock, has not been possible with 27 sites still under active management in 2018 (Fig. 5a). Many of these recalcitrant sites are found on inaccessible cliffs where herbicide spraying is difficult and less effective at dealing with the extensive seed and corm bank of this species. Finally, despite several decades of concerted action to eradicate E. crassipes, an aquatic ornamental appreciated by gardeners and aquaculturists alike, the number of sites under active management has shown a general increasing trend (Fig. 5b). Intriguingly, the trend for E. crassipes is mirrored by that of another NIPR aquatic ornamental, Salvinia molesta. The strong temporal correlation (r $=0.778$, df $21, P<0.001)$ likely reflects the importance of survey effort indicating that the species are more widespread than the data suggest. This is attributable to the species still being grown for ornament in garden ponds, the presence of illegal trade in the species and the fact that owners of active sites are not prepared to divulge the source of the plants, all of which lead to new populations establishing in the wild as material is dumped from garden ponds (Yamoah et al. 2013). The remaining species in NIPR programme also show variable outcomes, with eradication all but achieved in the case of a locally restricted submerged aquatic plant (Hydrilla verticilliata), progressing well for two rhizomatous grasses (Ehrhata villosa, Phragmites australis), and slower for species colonising difficult to access cliff sites (Bryonia dioica).

In addition to national eradication goals, the NIPR programme has targeted two species for sub-national eradication (Ceratophyllum demersum, Zizania latifolia). Yet sub-national eradication problems not only 
Fig. 5 Change in the number of active eradication sites in New Zealand since 1990 for a Sorghum halepense and Moraea flaccida and b Eichchornia crassipes and Salvinia molesta. Data from Yamoah et al. (2013)
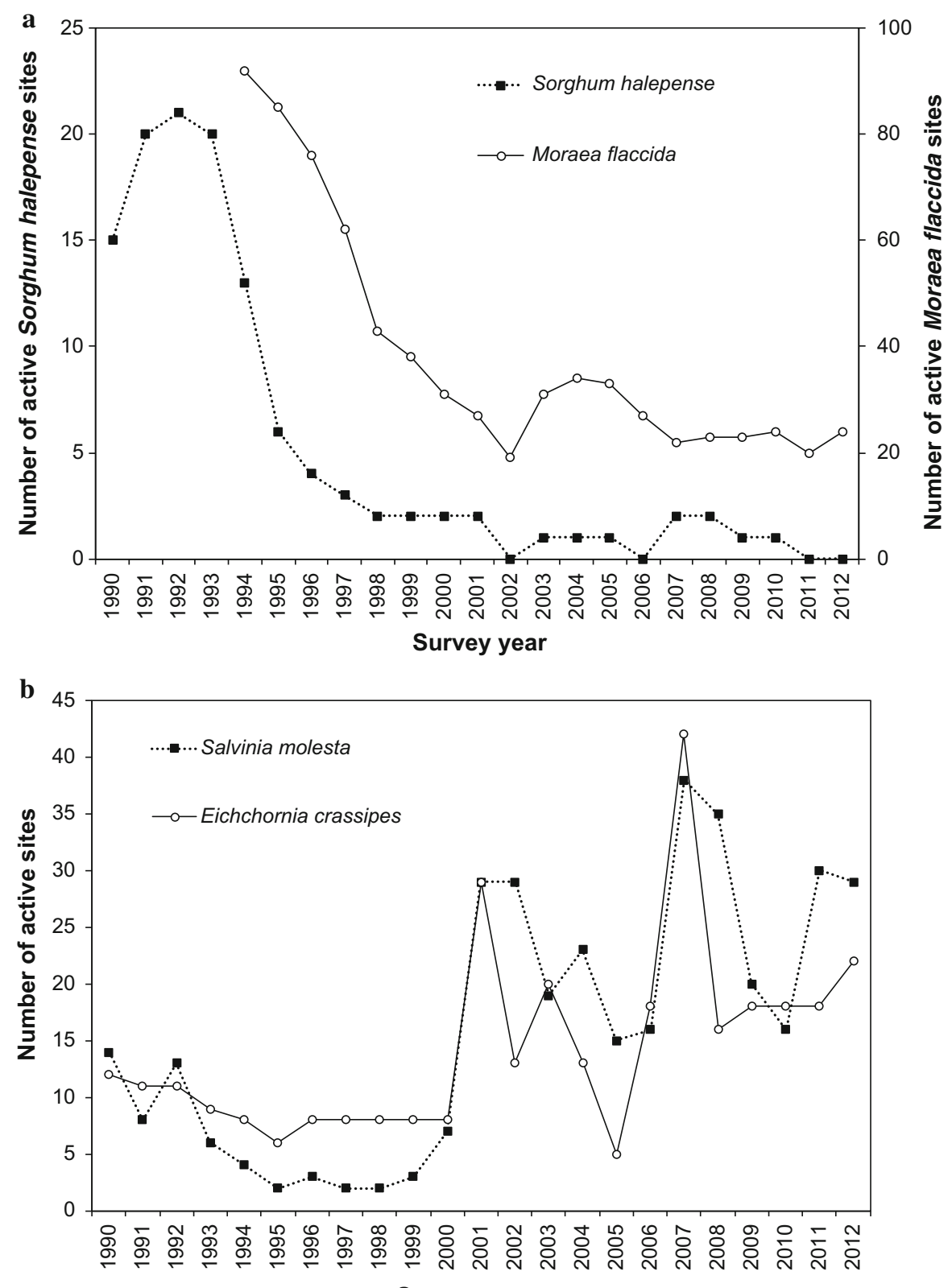

suffer from the constraints faced by national eradication programmes but have the additional problem that re-invasion from outside the target management area is a distinct possibility. Eradication of the submerged aquatic plant $C$. demersum from the South Island was achieved in 2008 but the species is widespread, and rapidly spreading in the North Island (de Winton et al. 2009). This presents a sizeable opportunity for reinvasion of the South Island and while waterfowl have the potential to move plant fragments across the $25 \mathrm{~km}$ separating the two islands, the greatest threat is through humans accidentally transporting material on boats and fishing gear. It therefore seems inevitable that the species will be re-introduced to the South Island and this imposes a significant cost in surveillance to ensure early detection and management of new introductions. 
Eradication programmes are also undertaken at a sub-national scale by Unitary Authorities and Regional Councils through their Regional Pest Management Plans (RPMP). These clearly work best where the target for eradication is only found in one region, where to all intents and purposes the programme is equivalent to national eradication. For example, Nuphar lutea, a mat-forming water lily, has only been found at two isolated waterbodies in one region where it is relatively well contained and the subject of an ongoing long-term eradication programme (Champion et al. 2013). However, such situations are not the norm, and in most cases sub-national eradication programmes target species that are more widely distributed. These programmes can be effective, where these are coordinated, supported by legislation (e.g. species on the NPPA list) and eradication is the goal in all regions where a species is known to be present (e.g. Hydrocleys nymphoides). However, as illustrated by the 65 year programme to eradicate $N$. trichotoma, even long-term, coordinated efforts can fail. Yet, there are many more situations where eradication is the goal in one region but not in one or more of its neighbours (e.g. Calotis lappulacea, Clematis vitalba, Pennisetum macrourum). Under these circumstances, there is a high probability that seeds and/or rhizomes might spread from one region to another through the long-distance movement of soil, gravel, livestock, machinery or people (Aikio et al. 2010a), making attempts to permanently eradicate a species from a region near impossible.

However, even where species are targeted for eradication, the chances of this occurring are often slim. For example, in the 1998 Canterbury district RPMP, eight species were targeted for eradication by 2003 (Williams and Braithwaite 2003). Only one species, a casual thistle $O$. tauricum, was eradicated from the region (and New Zealand) by the end of the period, but the remaining species still feature in the current 2018 RPMP, twenty years later (ECAN 2018). Only one of the species continues to be identified as an eradication target (Nymphoides geminata) while the remainder have shifted to lesser management goals such as only reducing their geographic distribution over time (Eragrostis curvulua, Baccharis halimifolia), maintaining ongoing management to reduce their impact (Calotis lappulacea, Tussilago farfara, Carthanus lanatus), or simply local control at valuable sites (Solanum marginatum). This downward cascade of management goals from eradication to lesser targets over time is typical of non-native plant species management, highlighting that the current approaches to prioritisation and subsequent action are flawed.

Reviews of the success or failure of non-native eradication campaigns tend to focus on designing an optimum management strategy (Panetta 2007, 2015) but there are a number of additional lessons that can be learned from these examples. First, national-scale eradication of widespread invasive non-native plants is possible but it requires evidence-based, nationally coordinated programmes that are backed by legislation and supported financially over several decades by a partnership among all stakeholders. Often the timeframes set out for non-native plant eradication are too short, raising expectations of rapid progress that, when not achieved, result in programmes being abandoned. Indeed, as eradication proceeds the marginal cost of managing remaining sites and populations increases but the scale (and priority) of the problem as perceived by stakeholders and policymakers declines. In the case of $N$. trichotoma, due to the longstanding management programmes, densities of plants are on average as low as 14 individuals per hectare. At this density, not only is search effort increased but the impact on production is relatively low. As a result, despite clear economic benefits to farmers of managing the species on their land, compliance rates for management are only $70 \%$. Farmers today complain less about the economic impact of $N$. trichotoma on livestock production than about the time and cost for compliance and how these resources could be better spent elsewhere on their farms.

Second, success is more likely where there is an engaged and supportive stakeholder community who will likely contribute to the eradication programme through surveillance, herbicide application and plant removal. The economic incentives to eradicate $S$. halepense and M. flaccida, that are primarily problems for arable and/or pastoral farmers, have undoubtedly helped achieve eradication. In contrast, despite initiatives such as the NPPA, there is a perceived reluctance among some gardeners who admire E. crassipes to report its presence on their property or indeed remove it. The importance of stakeholder buy-in in eradication programmes has to date been under-appreciated but clearly resistance to the management of highly appreciated ornamental plants (e.g. Buddleja davidii, 
T. fortunei) may be widespread (Lindemann-Matthies 2016). The constraints public perceptions might place on successful eradication outcomes should not be underestimated.

Third, while decisions regarding eradication targets are usually informed by a quantitative or semiquantitative prioritisation procedure, these have been invariably over-optimistic. While there are numerous, competing eradication prioritisation schemes (Booy et al. 2017; Cunningham et al. 2004; Darin et al. 2011; Nielsen and Fei 2015; Renteria et al. 2017), few have been tested with empirical eradication data and until this is undertaken the value of these tools is questionable. Furthermore, in New Zealand the Ministry for Primary Industries, Department of Conservation and Regional Councils use different criteria for prioritisation that reflect different weightings in relation economic and environmental outcomes. Finally, an adequate assessment of the risk of re-invasion from source populations not subject to eradication, be they ornamental plants in gardens (e.g. E. crassipes, $S$. molesta) or other naturalised populations (e.g. $C$. vitalba, $U$. pinnatifida), is essential since if the tools are not in place to mitigate these risks then eradication is likely to fail.

\section{Control: sustained but not sustainable?}

Where eradication is not feasible or has failed, management of non-native plants often focuses on control or maintenance management. Control aims to reduce the incidence, prevalence, or impact to a locally acceptable level as a result of deliberate management efforts and usually continued intervention measures are required to maintain the reduction. There are at least three reasons why control is preferred over eradication. A key situation where control is preferred over eradication is where the target non-native species also has high commercial value, particularly as forestry (Essl et al. 2010) or agriculture (Driscoll et al. 2014) species. In New Zealand, several economically valuable crop species are recognised as non-native environmental weeds (Fig. 6) and since there is no support among industry or policymakers for eradication, control is the only option. However, in most cases, control is a reflection that eradication is perceived to be impossible. Where a species is still spreading nationally, control strategies are often initially implemented to contain or reduce the geographic distribution of a non-native plant in a defined area over time (progressive control). There are

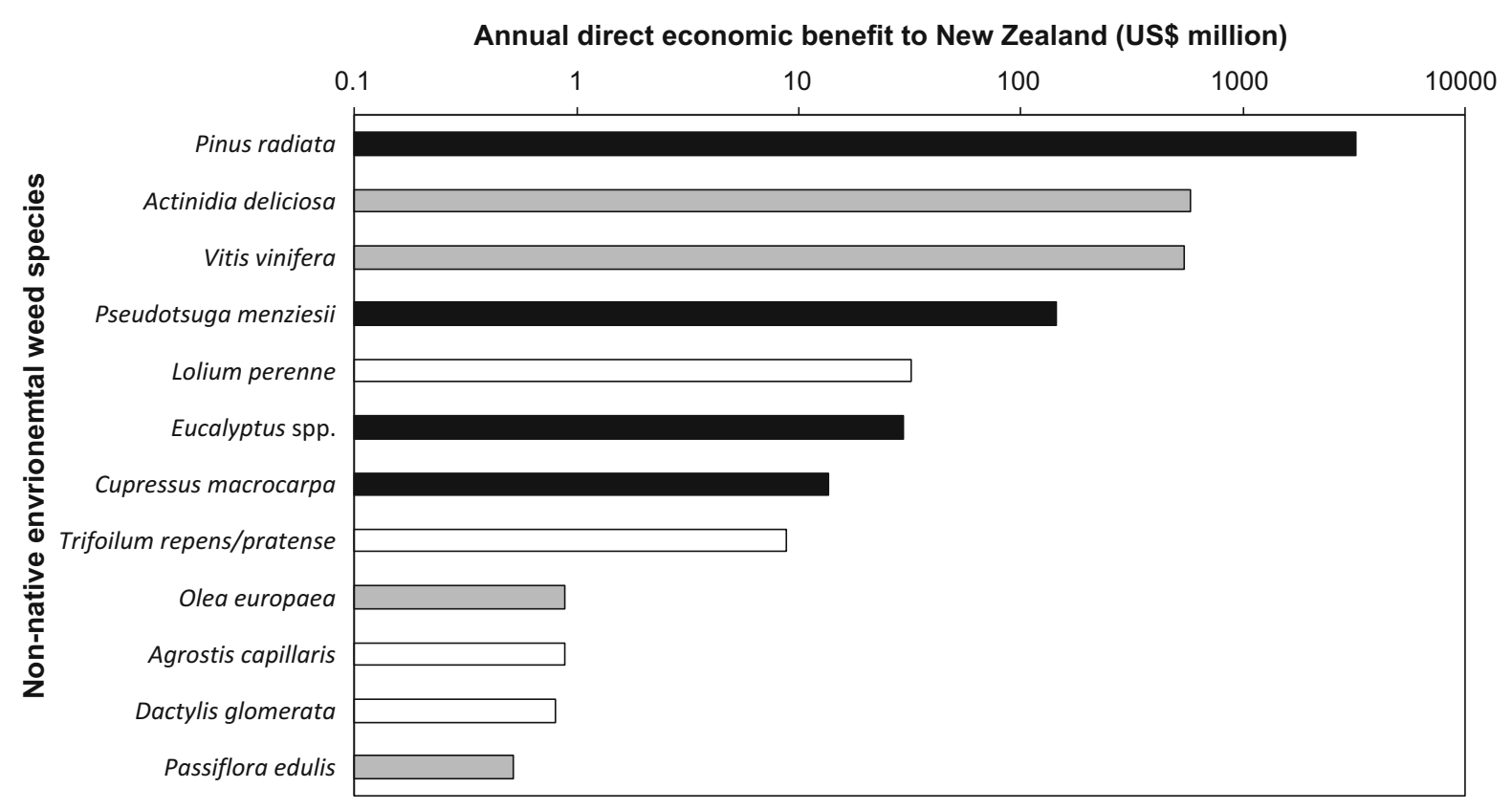

Fig. 6 The annual direct economic benefit (including domestic consumption and export value) to New Zealand (NZIER 2016) of 12 non-native environmental weeds listed by the Department of Conservation (Howell 2008). Bars are shaded to reflect the sector involved: black—forestry (Monterey pine, Douglas fir, Eucalyptus, Monterey cypress), grey-horticulture (kiwi fruit, grapes, olives, passionfruit), and white-pasture (ryegrass, red and white clovers, browntop, cocksfoot) 
considerable economic, environmental, and social benefits to containing and actively slowing non-native plant spread before impacts can be fully realised and widespread management is required. For example, a 2-year delay in the spread of the non-native freshwater diatom, Didymosphenia geminata, from the South to the North Island of New Zealand was estimated to represent a cost saving to the country of between US\$20 m and US\$100 m (Branson 2006). However, in many cases, if the non-native species has become well established, management aims to reduce impacts on wider economic and biodiversity values (sustained control) or protect specific locations, such as nature reserves (site-led control). As in many regions of the world, the primary management tools are mechanical, fire, grazing, chemical or biological control (Zimdahl 2018).

The release of relatively host-specific natural enemies as part of a coordinated biological control programme has the potential to deliver sustainable long-term, large-scale suppression of non-native plants. New Zealand has shown global leadership in the development and deployment of biological control programmes targeting non-native weeds. This leadership has been facilitated by politicians, regulators, land managers and industry stakeholders having an understanding of the economic benefits of biological control that has supported a streamlined regulatory process for the approval of the release of biological control agents (Ehlers et al. 2020). As a result, since 1929, 53 species of insect and eight fungi have been released for the biological control of 25 non-native plants in New Zealand (Landcare Research 2019). There have been dramatic successes with the widespread suppression of Jacobea vulgaris, Hypericum perforatum and Ageratina riparia while more local reductions in species abundance have been achieved for Alternanthera philoxeroides, Carduus nutans and Calluna vulgaris (Suckling 2013). While cynics might argue that most attempts at suppressing non-native plants using biological control have failed this misses the point that, in most cases, there were no realistic management alternatives and that every non-native plant suppressed by biological control is one that would otherwise have been imposing economic or biodiversity costs. A further concern is the possibility of biological control agents attacking native plant species. Several cases of non-target impacts have been documented in New Zealand, but most appear to have been anticipated as part of the risk assessment prior to release of the agent and subsequent impacts have been assessed as minor (Fowler et al. 2000; Paynter et al. 2008; Suckling and Sforza 2014). Indeed, today's more rigorous risk assessment protocols further limit the risk of non-target effects (Groenteman et al. 2011). Biological control is certainly no silver bullet for the control of non-native plants (especially species that are also commercially valuable) and it is likely that most non-native plant species will not experience large-scale suppression as a result of the release of biological control agents (Paynter et al. 2012) but it remains an important management tool for a relatively small proportion of non-native plant species.

Mechanical, fire, grazing and chemical control of non-native plants can be used in concert with biological control to bring about greater suppression of nonnative weeds than any single technique on its own. However, such integrated management has not been widely adopted outside of more intensive agricultural ecosystems, despite its potential promise (Bourdot et al. 2019; Chalak-Haghighi et al. 2008; Lake and Minteer 2018; Rees and Hill 2001). Outside of managed pastoral agroecosystems, vertebrate grazers and browsers can facilitate the establishment and spread of non-native plants in New Zealand rather than contribute to their control (Walker et al. 2003). One important exception is where introduced grass carp (Ctenopharyngdon idella) have been used to reduce the abundance of the non-native aquatic macrophyte Hydrilla verticillata (Hofstra and Clayton 2014). Similarly, few ecosystems in New Zealand are adapted to fire and anthropic burning leads to the spread of pyrophyllic non-native species at the expense of suppressing native species (Perry et al. 2014).

In contrast to the development of selective herbicides in agricultural systems that have been designed to control unwanted weeds without having a significant impact on the crop (Ghanizadeh and Harrington 2019), the tools for managing invasive plants in natural areas are often less precise. Existing commercial herbicide formulations are rarely completely effective against the wide range of non-native plants life-forms that impact biodiversity and ecosystem services in natural areas, with the results that often high application rates and/or repeat treatments are required. Such control approaches run the risk of nontarget damage to native species either through direct mortality or residual effects that inhibit natural 
regeneration, with the result that treated sites can be reinvaded by either the same or other non-native plants (McAlpine et al. 2018).

Furthermore, the goal of management should not simply be to achieve high mortality of the target nonnative species but also ensure the successful restoration of the ecosystem. Yet, without further intervention high mortality rates of non-native plant species following chemical or mechanical control may not result in the return of the original uninvaded plant community due to shifts in successional trajectories and/or reinvasion by non-native species (Burge et al. 2017; Dickie et al. 2013). Often the cost per unit area of site restoration is at least as much, if not greater, than the original control expenditure. Restoration costs can vary enormously from community-based projects costing at least US $\$ 10,000$ per hectare (at 2019 prices) to fully commercial projects (from planning to final establishment) that could be an order of magnitude more expensive (Davis and Muerck 2001). More than 600 community environmental groups across New Zealand are engaged in restoring degraded sites and most are involved in non-native plant control and the planting of native species, albeit in projects less than $0.5 \mathrm{~km}^{2}$ in size (Peters et al. 2015). Community environmental groups, through volunteer labour, provide a threefold return on any government financial support they receive and most groups believe they are making a meaningful contribution to conservation through their activities (HardieBoys 2010). Thus, while chemical and mechanical control methods will continue to play an important role in non-native plant control, engaging with local community environmental groups to undertake restoration will be essential to make the optimum use of limited operational resources.

Chemical, and to a lesser extent mechanical, control have been the mainstay of non-native plant management in New Zealand, but how effective have control efforts been to date? Although a wide range of stakeholders are involved in non-native plant management including government departments, local government, private landowners and community groups, the single most important player in the management of non-native plants in natural environments is the Department of Conservation (DOC). Approximately 8.5 million hectares of public conservation land are managed by DOC of which 928,000 ha $(10.9 \%)$ were under sustained management to control non-native plant species in 2018 (DOC 2018). Sustained management refers to the total area within which control programmes will be carried out and sustained over time but only a proportion of this area receives treatment in any one year.

Despite its strong commitment to manage nonnative plants on the public conservation estate, at the start of the millennium DOC estimated that only half of those high priority areas requiring control were receiving treatment and that at a third of those sites levels of control were insufficient to properly manage the problem (DOC 2000). The following years have seen progressive increases in both the area under sustained management and the area treated each year (Fig. 7a). At its peak in 2016, DOC had implemented a three-fold increase in the area treated each year resulting in a four-fold increase in the area under sustained management. While over this period, the number of non-native plant species on the public conservation estate are likely to have increased and become more widespread, the investment by DOC would still have addressed many of the concerns expressed at the start of the millennium, particularly in relation to targeting all priority areas. In 2016, DOC launched the "War on Weeds" campaign, yet a perverse outcome has subsequently seen the areas treated and under sustained management by DOC fall precipitously (Fig. 7a). While some of this change may be explained by more intensive effort in smaller areas, it also reflects changes in DOC priorities with resources being progressively shifted away from nonnative plants and towards more high-profile vertebrate pest control as well as poor planning that led to unfilled staff vacancies and a shortage of contractors to carry out the work (DOC 2018). Indeed, the last year that DOC actually met its planned target for the area treated for non-native plant control was as far back as 2013. Furthermore, since 2000 the proportion of the sustained area treated each year has declined $\left(\mathrm{R}^{2}\right.$ $\left.0.364, \mathrm{~F}_{(1,18)}=10.30, P<0.01\right)$ indicating that the frequency of repeat visits to treatment sites has more or less halved from around once every two years to once every four years (Fig. 7b). Such trends suggest DOC is currently losing the "War on Weeds" and a reduction in areas treated or under sustained management, even for a few years, will enable non-native plants to recolonise sites previously cleared or spread to new areas effectively undoing all the work achieved in the last decade. 
Fig. 7 Variation in effort in non-native plant species management by the Department of Conservation (DOC) as illustrated by a a recent progressive decline in both the area treated and area under sustained control, and $\mathbf{b}$ a trend for a smaller total area under sustained control to be treated in any year. Data from DOC annual reports available at https:// www.doc.govt.nz/about-us/ our-role/corporate-

publications/annual-reportsarchive
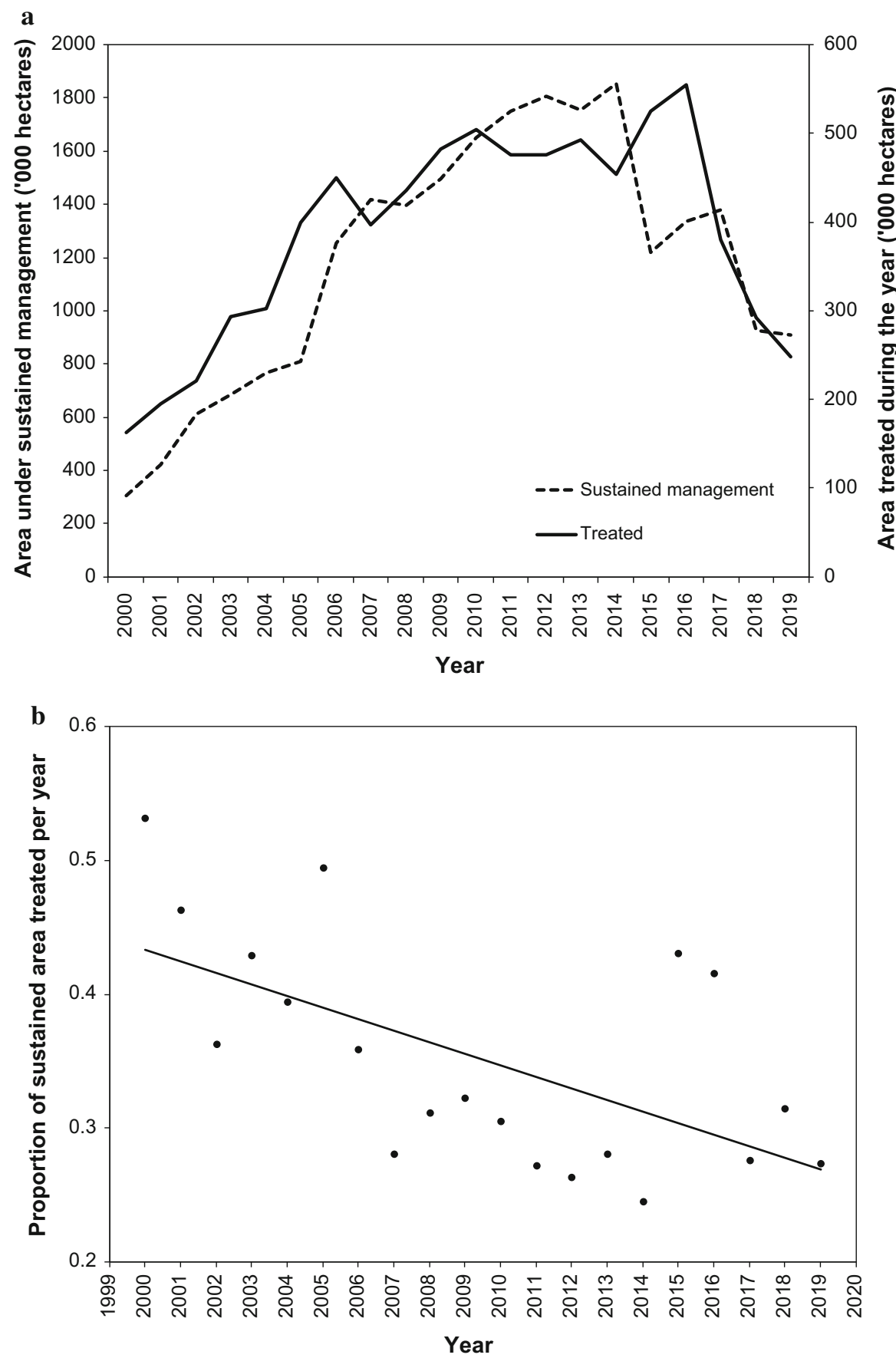

How effective are the control efforts managed by DOC? A quantitative assessment of the effectiveness of 111 non-native plant control campaigns in protected areas managed by DOC revealed that after a decade, 21 programmes had been discontinued, almost half of the remainder had not managed any significant progress and only four programmes achieved complete control in the protected area (Howell 2012). A major weakness of site-led control programmes is the failure to account and control for the likelihood of reinvasion. This is especially important when targeting control in protected areas since these often exist 


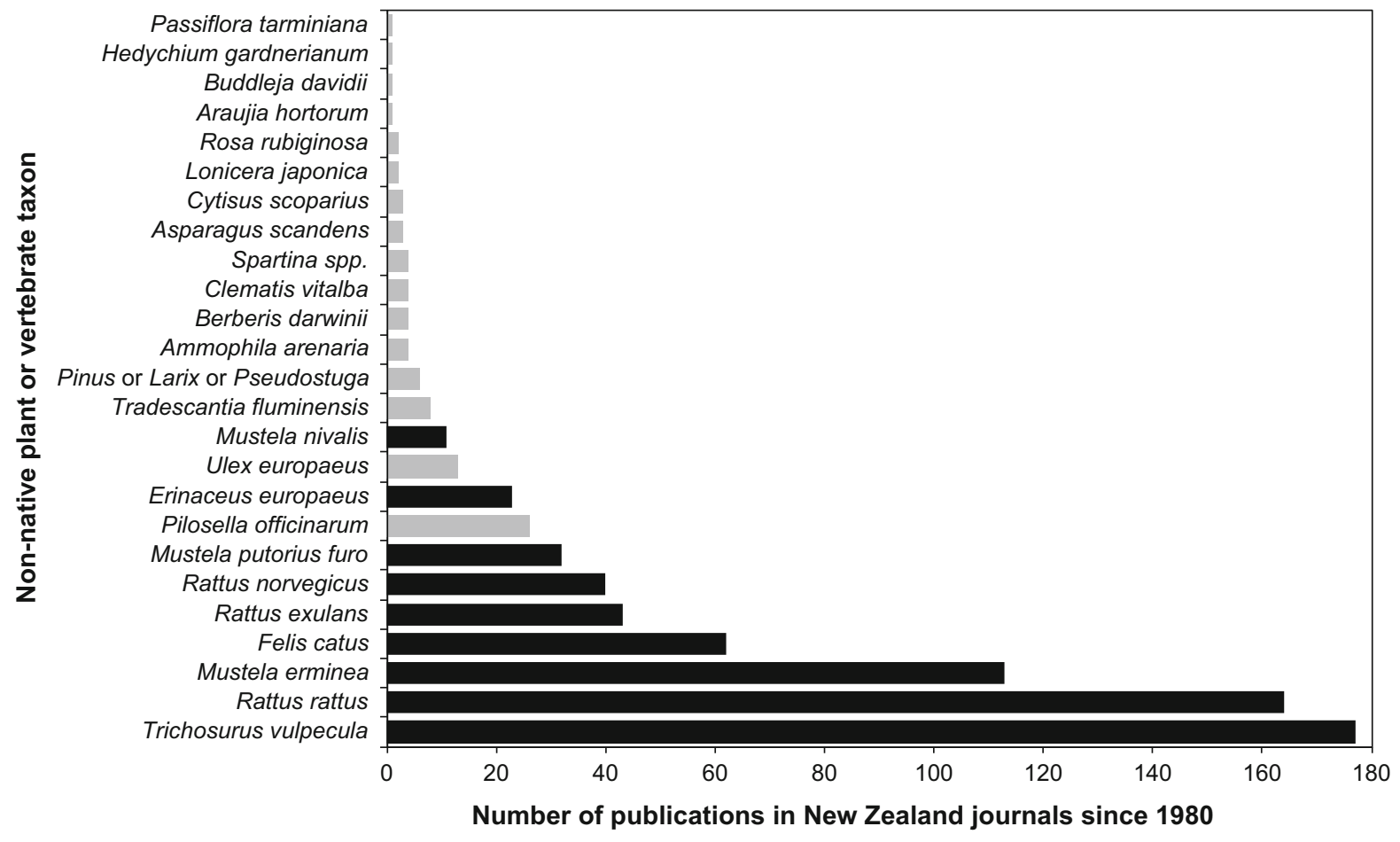

Fig. 8 Number of papers addressing specific non-native vertebrate predators (black bars) and non-native plant species (grey bars) published since 1980 in the New Zealand Journal of Ecology (both taxonomic groups, with a total of 1132 papers published since 1980), New Zealand Journal of Botany (plants

within a wider human modified landscape that can host many neighbouring source populations of the nonnative species targeted for control. This is also true in the marine environment. New incursions of the nonnative seaweed Undaria pinnatifida from naturalised populations in the South Island were the primary reason why a seven year DOC-led control programme failed to prevent the spread of the species around Stewart Island (Hunt et al. 2009).

Many managers hope that future technology developments such as robotics, bioherbicides, nanotechnology, RNAi, and gene editing (Korres et al. 2019) will present them with a set of silver bullets that will lead to a radical step change in the success of non-native plant species eradication and control campaigns. While this may be true for cosmopolitan weeds of agriculture that represent a global market for any new technology, it may be harder to mobilise the investment required to target non-native plant species in natural areas, especially where these are only of national, rather than worldwide, interest. In New Zealand, investment only, with a total of 1885 papers published since 1980) and New Zealand Journal of Zoology (vertebrate predators only, with a total of 1968 papers published since 1980). Searches were undertaken using Web of Knowledge on 2/12/19 using the species binomial name and associated synonyms as search terms

in research on non-native plants (as indicated by research outputs in national journals) is an order of magnitude less than for non-native vertebrate predators (Fig. 8). Expenditure on vertebrate predator management, technological development, and impact assessment is supported by considerable government and philanthropic funding (Peltzer et al. 2019) that dwarves the level of support for similar initiatives addressing non-native plants species. Thus, a significant reshaping of the funding landscape would be required to deliver on the potential of new technologies for non-native plant species management in New Zealand.

\section{Global lessons from New Zealand in the management of non-native plants}

Many nations across the world are attempting to manage the economic and environmental threats posed by non-native plants (Pysek et al. 2017), but 
New Zealand is better placed than most to address this problem. As a relatively wealthy island nation, it can enforce biosecurity protocols at its border to prevent the entry of unwanted species, whereas for coterminous mainland regions the spread of non-native plant species often occurs across jurisdictional boundaries. There is strong political, legislative, industry and public support for addressing the problems posed by non-native plants (MPI 2016). The country is ranked among the top nations in the world in terms of governance, particularly political stability, regulatory quality, government effectives and the rule of law (Kaufmann et al. 2008) and this ensures biosecurity policies are undertaken effectively. Furthermore, while there are concerns regarding the erosion of national taxonomic expertise, New Zealand still retains strong botanical expertise and hosts seven national herbaria that house close to 1.5 million holdings (Nelson et al. 2015) that together assist in identifying recently naturalised non-native species (Heenan et al. 2008) and significantly help further the understanding of plant invasions (Aikio et al. 2010a, b, 2012). Finally there is broad public support, at least by community environmental groups, for the management of non-native plants using biological control, chemical and mechanical methods (Peters et al. 2015). Few countries in the world have all these advantages, particularly developing nations (Early et al. 2016; Paini et al. 2016). Thus, to what extent can the New Zealand experience be translated to other regions of the world?

A key message is that despite these advantages for the management of non-native plants in New Zealand, there remains a significant disparity between the considerable effort invested in prevention, eradication and control, and the limited outcomes in terms of reduced naturalisation, spread and impacts. The fact that this is the case in New Zealand where non-native plants are widely acknowledged by policymakers and the public to be a major environmental and economic problem does not bode well for regions where the issue has a lower national profile. However, irrespective of the political or economic situation a country might face there is scope to improve the current approach to non-native plant species management across the world. In particular, managers need to overcome several cognitive biases that potentially limit the effectiveness of their interventions. Cognitive biases, such as framing, anchoring and confirmation bias, have previously been shown to constrain the transparency and robustness of weed risk assessment (Hulme 2012) but a suite of five additional biases also hamper effective eradication and control decision-making: intervention, hindsight, linearity, and familiarity biases as well as planning fallacy.

It is often tempting once one or more non-native plants species has been identified as posing a significant problem to initiate a removal programme. Organisations can often feel pressure to be seen to be doing something to address a perceived non-native species problem. Under such circumstances, decisionmaking can suffer from intervention bias, where land managers believe incorrectly that they know how to fix the problem and that the system would benefit from intervention. Yet in all non-native plant species management programmes, the first action should be to identify the drivers of invasion since the target nonnative species may be as much a symptom as a cause of ecosystem change. Thus forest fragmentation (Williams and Buxton 1995), increased disturbance (Jesson et al. 2000), disrupted river flows (Brummer et al. 2016), eutrophication of soils and water (de Winton et al. 2012), altered fire frequencies (Williams 1992), and changes in the abundance of grazers or browsers (Bellingham and Coomes 2003; Walker et al. 2016) can all act as drivers of plant invasion (Hulme 2006). Unless these drivers are managed, then despite successful removal of the target species, ecosystems will remain prone to re-invasion, either by the same or by other plant species. A further possibility is that without any intervention, native plant succession may replace the target non-native species. The conditions under which native succession may replace non-native species remain poorly understood but likely include the absence of any existing barriers to native plant regeneration (e.g. fire or browsing), appropriate soil fertility, climate suitability, and the availability of native plant propagules (Wotton and McAlpine 2013). The potential for natural regeneration through native succession should be considered in any management programme and options to facilitate this process could include planting native species to overcome dispersal limitation. Unfortunately, it is hard to persuade stakeholders that the non-native plant problem will resolve itself in two to three decades when they want the ecosystem restored within only a few years.

Assuming that the non-native plant species is a driver rather than passenger of environmental change, 
it is widely recognised that acting promptly to address plant invasions will significantly reduce long-term costs (Harris and Timmins 2009). When faced with widespread plant invasions today, there is a frequent tendency to ask why management interventions were not implemented earlier when the species would have been more straightforward to manage. However, this view suffers from hindsight bias that leads individuals to view past events as more predictable than they actually were at the time. Indeed, it is likely that managers face similar unpredictability today as they did several decades ago. A key area of uncertainty is that often decisions made today underestimate the scale of the invasion problem in the future, often termed a linearity bias. A linearity bias occurs when decision-makers fail to grasp that once non-native species begin to spread, the rate at which their ranges expand is often non-linear and accelerating (Aikio et al. 2010b) which poses a huge cost on any intervention delay. Thus, managers may often be surprised at how quickly a non-native species has spread during only a few years, by which time management options become limited. To address both hindsight and linearity bias, more robust forecasts of population trajectories are needed for those non-native species that are currently rare or geographically restricted. Two complimentary approaches could be adopted that target locally distributed "sleeper weeds". First, given that there are at least 650 nonnative plant species that are casual and do not form persistent populations in New Zealand, it may be sensible to identify the species for which persistence is currently constrained by environmental factors that are likely to be relaxed under future climate change (Hulme 2017a; Sheppard et al. 2016). While the potential role of climate change on the distribution of widespread non-native plants in New Zealand has been frequently modelled (Kriticos et al. 2004, 2011; Potter et al. 2009), few studies have projected the distribution of more locally distributed species (Sheppard 2013). Second, since the longer a species has been naturalised, the more widely distributed it has become in New Zealand (Williams and Cameron 2006), it would make sense to target species naturalised in only the last 50 years that are currently found across a limited area. Initial targets could be a subset of NPPA species found in only one New Zealand region (Fig. 4). In both approaches it would be essential to understand the pathways of introduction, particularly where species are garden escapes, to ensure this source of future plants was closed.

However, programmes to eradicate or control nonnative plants, even when rare or geographically localised, need to avoid a cognitive bias termed the planning fallacy. In the planning fallacy, the scale of the task is severely underestimated leading to significant time and cost overruns as well as failure to realise the benefits of management actions. In New Zealand, both unsuccessful (e.g. N. trichotoma) and successful (e.g. S. halepense) eradication programmes have taken many more decades and significantly greater resourcing than originally envisaged. Large-scale non-native plant management imposes significant operational costs on those authorities tasked to address the problem. Land managers therefore need to shift their perspective from viewing such long-term programmes as being exceptions to accepting that, to have a chance of success, management needs to be planned over several decades not years. Many management programmes are initiated with a large injection of operational resources to gain initial momentum and then often fall back down to much lower levels of funding. Large-scale control strategies should be based on the likely baseline level of funding rather than any generous kick-start funds that are usually unsustainable in the long-term. Where funding cannot be committed over many years, long-term programmes should be split into a series of consecutive timesteps with realistic, measurable objectives that can be achieved over shorter financial timeframes but that together lead to the overall management goal. Insufficient long-term funding is frequently seen as the primary barrier to successful non-native plant management, with the costs often resting on a single organisation. A more sustainable approach to supporting long-term management is through building partnerships among national and local government, nongovernmental organisations, industry, indigenous groups, environmental trusts, landowners and the general public. This is currently the approach adopted in a national programme to combat invasive nonnative conifers in New Zealand (Peltzer 2018). A coordinated approach among multiple stakeholders is likely to be more cost-effective, and the contributions made by different stakeholders may range from financial input to contributions in kind through 
volunteer labour, loan of equipment and or training support.

The willingness of stakeholders to support nonnative plant management tends to be greatest where there is an understanding of the impacts upon provisioning services such as agricultural productivity, timber yields, or water availability (Hulme and Vilà 2017; Mason et al. 2017). Where impacts act upon components of biodiversity, a major challenge is overcoming familiarity bias where individuals are only concerned about those species with which they are familiar. Unfortunately, most non-native plants and the endemic native plant species they critically threaten are unfamiliar to the general public (Table 1). Many nationally critical species don't even have common names and those that do may not capture the imagination (de Lange et al. 2010). It is hard to imagine the general public becoming mobilised to "Save the Sneezeweed" despite its highly threatened status. Potentially focusing attention on the threats posed to a wider suite of more familiar taxa, such as endemic orchids, may be more effective. Where this is not possible, focusing on those threatened ecosystems where non-native plants are understood to be significant drivers of native species losses (e.g. inland outwash gravels, shell barrier beaches and old tephra plains) rather than passengers of wider degradation (Wiser et al. 2013) could be of value. Nevertheless, familiarity can sometimes work against management where non-native plant species with attractive blooms such as Lupinus polyphyllus are viewed by the general public as attractive features of the landscape (Caruso 2006).

In summary, while underinvestment in the underpinning science and technology of managing nonnative plant species in New Zealand remains a significant constraint on successful eradication and control campaigns, there is still scope to improve upon the status quo. Key recommendations to mobilise and maintain future actions include: (a) the ability to identify when an initially regional invasion is likely to become a national issue as more regions encounter similar problems; (b) having dramatic estimates of the potential extent of the problem in the absence of any coordinated management; (c) quantifying the problem in terms of the loss of values (landscape, nature, water) that strike a chord with the public and policymakers; and (d) clear indicators of successful progress that can be reported regularly to all stakeholders. These recommendations are equally valid for other regions of the world, but by embracing these recommendations the opportunity remains for New Zealand to once again show global leadership in the management of non-native plant species.

Acknowledgements I would like to thank the Royal Society Te Apārangi for its support through the Leonard Cockayne Lecture award that enabled me to focus on reviewing the history and current state of plant invasions in New Zealand as well as the opportunity to present these ideas to a wide range of stakeholders at over a dozen public lectures across the North and South Islands of New Zealand. This work was also funded through Grant C09X1611 "Winning against Wildings" from the New Zealand Ministry of Business, Innovation and Employment.

Open Access This article is licensed under a Creative Commons Attribution 4.0 International License (https:// creativecommons.org/licenses/by/4.0/), which permits use, sharing, adaptation, distribution and reproduction in any medium or format, as long as you give appropriate credit to the original author(s) and the source, provide a link to the Creative Commons licence, and indicate if changes were made. The images or other third party material in this article are included in the article's Creative Commons licence, unless indicated otherwise in a credit line to the material. If material is not included in the article's Creative Commons licence and your intended use is not permitted by statutory regulation or exceeds the permitted use, you will need to obtain permission directly from the copyright holder. To view a copy of this licence, visit http://creativecommons.org/licenses/by/4.0/.

\section{References}

Aikio S, Duncan RP, Hulme PE (2010a) Herbarium records identify the role of long-distance spread in the spatial distribution of alien plants in New Zealand. J Biogeogr 37:1740-1751

Aikio S, Duncan RP, Hulme PE (2010b) Lag-phases in alien plant invasions: separating the facts from the artefacts. Oikos 119:370-378

Aikio S, Duncan RP, Hulme PE (2012) The vulnerability of habitats to plant invasion: disentangling the roles of propagule pressure, time and sampling effort. Glob Ecol Biogeogr 21:778-786

Allan HH (1936) Indigene versus alien in the New Zealand plant world. Ecology 17:187-193

Allan HH (1940) A handbook of the naturalised flora of New Zealand. DSIR, Wellington

Ansong M, Pergl J, Essl F et al (2019) Naturalized and invasive alien flora of Ghana. Biol Invasions 21:669-683

Barina Z, Rakaj M, Somogyi G et al (2014) The alien flora of Albania: history, current status and future trends. Weed Res 54:196-215 
Bellingham PJ, Coomes DA (2003) Grazing and community structure as determinants of invasion success by Scotch broom in a New Zealand montane shrubland. Divers Distrib 9:19-28

Booy O, Mill AC, Roy HE et al (2017) Risk management to prioritise the eradication of new and emerging invasive non-native species. Biol Invasions 19:2401-2417

Bourdot GW, Saville DJ (2016) Nassella trichotoma in modified tussock grasslands in New Zealand: a case study in landscape-scale invasive plant population monitoring. Weed Res 56:395-406

Bourdot GW, Lamoureaux SL, Jackman SD et al (2019) $R a$ nunculus acris control in dairy pasture - a comparison of herbicides, plant growth promoters, a bioherbicide and pregraze mowing. New Zealand J Agric Res 62:184-199

Bradbury M (1995) A history of the garden in New Zealand. Penguin Books, Auckland

Branson J (2006) Didymosphenia geminata economic impact assessment. New Zealand Institute of Economic Research, Wellington

Brummer TJ, Byrom AE, Sullivan JJ et al (2016) Alien and native plant richness and abundance respond to different environmental drivers across multiple gravel floodplain ecosystems. Divers Distrib 22:823-835

Burge OR, Bodmin KA, Clarkson BR et al (2017) Glyphosate redirects wetland vegetation trajectory following willow invasion. Appl Veg Sci 20:620-630

Burgiel SK, Perrault AM (2011) Black, white and gray lists. In: Simberloff D, Rejmanek M (eds) Encyclopedia of biological invasions. University of California Press, Berkeley, pp 75-77

Camarda I, Cossu TA, Carta L et al (2016) An updated inventory of the non-native flora of Sardinia (Italy). Plant Biosyst 150:1106-1118

Caruso BS (2006) Project river recovery: restoration of braided gravel-bed river habitat in New Zealand's high country. Environ Manag 37:840-861

Chalak-Haghighi M, Van Ierland EC, Bourdot GW et al (2008) Management strategies for an invasive weed: a dynamic programming approach for Californian thistle in New Zealand. N Z J Agric Res 51:409-424

Champion PD (2018) Knowledge to action on aquatic invasive species: island biosecurity: the New Zealand and South Pacific story. Manag Biol Invasions 9:383-394

Champion PD, Clayton JS (2001) Border control for potential aquatic weeds. Stage 2. Weed risk assessment. Science for conservation 141. Department of Conservation, Wellington, New Zealand

Champion P, Rowe D, Smith B et al (2013) Freshwater pests of New Zealand. NIWA, Wellington

Cockayne L (1910) New Zealand plants and their story. John Mackay, Wellington

Cockayne L, Simpson G, Thomson JS (1932) Some New Zealand indigenous-induced weeds and indigenous-induced modified and mixed plant-communities. Bot J Linn Soc 49:13-45

Council Biosecurity (2003) Tiakina Aotearoa protect new Zealand: the biosecurity strategy for New Zealand. Biosecurity Council, Wellington, New Zealand
Cunningham DC, Barry SC, Woldendorp G et al (2004) A framework for prioritizing sleeper weeds for eradication. Weed Technol 18:1189-1193

Darin GMS, Schoenig S, Barney JN et al (2011) WHIPPET A novel tool for prioritizing invasive plant populations for regional eradication. J Environ Manag 92:131-139

Davis M, Muerck C (2001) Protecting and restoring our natural heritage: a practical guide. Department of Conservation, Wellington

Dawson B (2010) A history of gardening in New Zealand. Random House, Auckland

de Lange PJ, Heenan PB, Norton DA et al (2010) Threatened plants of New Zealand. Canterbury University Press, Christchurch

de Winton MD, Champion PD, Clayton JS et al (2009) Spread and status of seven submerged pest plants in New Zealand lakes. N Z J Mar Freshw Res 43:547-561

de Winton MD, Clayton JS, Edwards T (2012) Incorporating invasive weeds into a plant indicator method (LakeSPI) to assess lake ecological condition. Hydrobiologia 691:47-58

Dickie IA, St John MG, Yeates GW et al (2013) Belowground legacies of Pinus contorta invasion and removal result in multiple mechanisms of invasional meltdown. AoB PLANTS 6:plu056

Dickson M (2009) The plants biosecurity index. N Z Gard J 12:8-9

Diez JM, Williams PA, Randall RP et al (2009) Learning from failures: testing broad taxonomic hypotheses about plant naturalization. Ecol Lett 12:1174-1183

DOC (2000) Department of conservation annual report. Department of Conservation, Wellington

DOC (2018) Department of conservation Te Papa Atawhai annual report. Department of Conservation, Wellington

Douglas J (2005) Exotic plants are the lifeblood of New Zealand: less regulation is needed to allow more new species into this country. N Z Gard J 8:2-6

Driscoll DA, Catford JA, Barney JN et al (2014) New pasture plants intensify invasive species risk. Proc Natl Acad Sci USA 111:16622-16627

Early R, Bradley BA, Dukes JS et al (2016) Global threats from invasive alien species in the twenty-first century and national response capacities. Nat Commun 7:12485

Easton B (2011) Exercises in New Zealand's demography and economic history. N Z Popul Rev 37:173-182

ECAN (2018) Canterbury regional pest management plan 2018-2038. Canterbury Regional Council, Christchurch

Ehlers GAC, Caradus JR, Fowler SV (2020) The regulatory process and costs to seek approval for the development and release of new biological control agents in New Zealand. Biocontrol 65:1-12

Essl F, Moser D, Dullinger S et al (2010) Selection for commercial forestry determines global patterns of alien conifer invasions. Divers Distrib 16:911-921

Fowler SV, Syrett P, Hill RL (2000) Success and safety in the biological control of environmental weeds in New Zealand. Aust Ecol 25:553-562

Fraser A (2002) The effectiveness of the brochure 'garden escapes'. Science for conservation 205. Department of Conservation, Wellington 
Gatehouse HAW (2008) Ecology of the naturalisation and geographic distribution of the non-indigenous seed plant species of New Zealand. Lincoln University, unpublished $\mathrm{Ph} . \mathrm{D}$. thesis

Ghanizadeh H, Harrington KC (2019) Weed management in New Zealand pastures. Agronomy 9:448

Glen AS, Atkinson R, Campbell KJ et al (2013) Eradicating multiple invasive species on inhabited islands: the next big step in island restoration? Biol Invasions 15:2589-2603

Groenteman R, Fowler SV, Sullivan JJ (2011) St. John's wort beetles would not have been introduced to New Zealand now: a retrospective host range test of New Zealand's most successful weed biocontrol agents. Biol Control 57:50-58

Hardie-Boys N (2010) Valuing community group contributions to conservation. Science for conservation 299. Department of Conservation, Wellington

Harris S, Timmins SM (2009) Estimating the benefit of early control of all newly naturalised plants. Science for Conservation 292. Department of Conservation, Wellington

Heenan PB, de Lange PJ, Cameron EK et al (2008) Checklist of dicotyledons, gymnosperms, and pteridophytes naturalised or casual in New Zealand: additional records 2004-06. N Z J Bot 46:257-283

Hejda M (2013) Do species differ in their ability to coexist with the dominant alien Lupinus polyphyllus? A comparison between two distinct invaded ranges and a native range. NeoBiota 17:39-55

Hofstra D, Clayton J (2014) Native flora and fauna response to removal of the weed Hydrilla verticillata (L.f.) Royle in Lake Tutira. Hydrobiologia 737:297-308

Howell CJ (2008) Consolidated list of environmental weeds in New Zealand. DOC research \& development series 292. Department of Conservation Wellington

Howell CJ (2012) Progress toward environmental weed eradication in New Zealand. Invasive Plant Sci Manag $5: 249-258$

Hulme PE (2006) Beyond control: wider implications for the management of biological invasions. J Appl Ecol 43:835-847

Hulme PE (2011) Addressing the threat to biodiversity from botanic gardens. Trends Ecol Evol 26:168-174

Hulme PE (2012) Weed risk assessment: a way forward or a waste of time? J Appl Ecol 49:10-19

Hulme PE (2017a) Climate change and biological invasions: evidence, expectations, and response options. Biol Rev 92:1297-1313

Hulme PE (2017b) Incursion response in New Zealand. In: Wilson RJ, Panetta FD, Lindgren C (eds) Detecting and responding to alien plant incursions. Cambridge University Press, Cambridge, pp 7-11

Hulme PE, Vilà M (2017) Integrating the impacts of non-native species on ecosystem services into environmental policy. In: Vilà M, Hulme PE (eds) Impact of biological invasions on ecosystem services. Springer, Cham, pp 327-341

Hulme PE, Brundu G, Carboni M et al (2018) Integrating invasive species policies across ornamental horticulture supply chains to prevent plant invasions. J Appl Ecol 55:92-98

Hunt L, Chadderton L, Stuart M et al (2009) Results of an attempt to control and eradicate Undaria pinnatifida in
Southland, New Zealand, April 1997-November 2004. Department of Conservation, Wellington

James TK, Champion PD, Bullians M et al (2012) Weed biosecurity breach through coco peat imports. Pak J Weed Sci Res 18:249-256

Jesson L, Kelly D, Sparrow A (2000) The importance of dispersal, disturbance, and competition for exotic plant invasions in Arthur's Pass National Park, New Zealand. N Z J Bot 38:451-468

Kaufmann D, Kraay A, Mastruzzi M (2008) Governance matters VII: aggregate and individual governance indicators 1996-2007. World Bank, Washington DC

Kirk T (1895) The displacement of species in New Zealand. Trans N Z Inst 28:1-27

Korres NE, Burgos NR, Travlos I et al (2019) New directions for integrated weed management: modern technologies, tools and knowledge discovery. Adv Agron 155:243-319

Kriticos DJ, Lamoureaux S, Bourdot GW et al (2004) Nassella tussock: current and potential distributions in New Zealand. N Z Plant Prot 57:81-88

Kriticos DJ, Watt MS, Potter KJB et al (2011) Managing invasive weeds under climate change: considering the current and potential future distribution of Buddleja davidii. Weed Res 51:85-96

Lake EC, Minteer CR (2018) A review of the integration of classical biological control with other techniques to manage invasive weeds in natural areas and rangelands. Biocontrol 63:71-86

Landcare Research (2019) The biological control of weeds book: a New Zealand guide. Landcare Research, Lincoln

Leach H (2005) Gardens without weeds? Pre-European Maori gardens and inadvertent introductions. $N \mathrm{Z}$ J Bot 43:271-284

Lindemann-Matthies P (2016) Beasts or beauties? Laypersons' perception of invasive alien plant species in Switzerland and attitudes towards their management. NeoBiota 29:15-33

Mason NWH, Palmer DJ, Vetrova V et al (2017) Accentuating the positive while eliminating the negative of alien tree invasions: a multiple ecosystem services approach to prioritising control efforts. Biol Invasions 19:1181-1195

McAlpine KG, Lamoureaux SL, Timmins SM et al (2018) Can a reduced rate of herbicide benefit native plants and control ground cover weeds? N Z J Ecol 42:204-213

MPI (2016) Biosecurity 2025: direction statement for New Zealand's biosecurity system. Ministry for Primary Industries, Wellington

Nelson WA, Breitwieser I, Fordyce RE et al (2015) National taxonomic collections in New Zealand. Royal Society of New Zealand, Wellington

Newfield MJ, Champion PD (2010) Risk assessment for the New Zealand National Pest Plant Accord: which species should be banned from sale? Plant Prot Q 25:75-78

Nielsen AM, Fei SL (2015) Assessing the flexibility of the analytic hierarchy process for prioritization of invasive plant management. Neobiota 27:25-36

Nielsen JA, Grondahl E, Callaway RM et al (2017) Home and away: biogeographical comparison of species diversity in Thymus vulgaris communities. Biol Invasions 19:2533-2542 
NPPA (2012) National plant pest accord manual. National Plant Pest Accord, Wellington

NZIER (2016) How valuable is that plant species? Application of a method for enumerating the contribution of selected plant species to New Zealand's GDP. Ministry of Primary Industries, Wellington

Paini DR, Sheppard AW, Cook DC et al (2016) Global threat to agriculture from invasive species. Proc Natl Acad Sci USA 113:7575-7579

Panetta FD (2007) Evaluation of weed eradication programs: containment and extirpation. Divers Distrib 13:33-41

Panetta FD (2015) Weed eradication feasibility: lessons of the 21st century. Weed Res 55:226-238

Panetta FD, Timmins SM (2004) Evaluating the feasibility of eradication for terrestrial weed incursions. Plant Prot Q 19:5-11

Paynter Q, Gourlay AH, Oboyski PT et al (2008) Why did specificity testing fail to predict the field host-range of the gorse pod moth in New Zealand? Biol Control 46:453-462

Paynter Q, Overton JM, Hill RL et al (2012) Plant traits predict the success of weed biocontrol. J Appl Ecol 49:1140-1148

Peltzer DA (2018) Ecology and consequences of invasion by non-native (wilding) conifers in New Zealand. J N Z Grassl 80:39-46

Peltzer DA, Bellingham PJ, Dickie IA et al (2019) Scale and complexity implications of making New Zealand predatorfree by 2050. J R Soc N Z 49:412-439

Perry GLW, Wilmshurst JM, McGlone MS (2014) Ecology and long-term history of fire in New Zealand. $\mathrm{N} \mathrm{Z} \mathrm{J} \mathrm{Ecol}$ 38:157-176

Peters MA, Hamilton D, Eames C (2015) Action on the ground: a review of community environmental groups' restoration objectives, activities and partnerships in New Zealand. N Z J Ecol 39:179-189

Potter KJB, Kriticos DJ, Watt MS et al (2009) The current and future potential distribution of Cytisus scoparius: a weed of pastoral systems, natural ecosystems and plantation forestry. Weed Res 49:271-282

Pysek P, Chytry M, Pergl J et al (2012) Plant invasions in the Czech Republic: current state, introduction dynamics, invasive species and invaded habitats. Preslia 84:575-629

Pysek P, Pergl J, Essl F et al (2017) Naturalized alien flora of the world: species diversity, taxonomic and phylogenetic patterns, geographic distribution and global hotspots of plant invasion. Preslia 89:203-274

Rees M, Hill RL (2001) Large-scale disturbances, biological control and the dynamics of gorse populations. J Appl Ecol 38:364-377

Renteria JL, Rouget M, Visser V (2017) Rapid prioritization of alien plants for eradication based on climatic suitability and eradication feasibility. Aust Ecol 42:995-1005

Robertson PA, Adriaens T, Lambin X et al (2017) The largescale removal of mammalian invasive alien species in Northern Europe. Pest Manag Sci 73:273-279

Saunders JT, Greer G, Bourdôt G et al (2017) The economic costs of weeds on productive land in New Zealand. Int $\mathbf{J}$ Agric Sustain 15:380-392

Seebens H, Blackburn TM, Dyer EE et al (2017) No saturation in the accumulation of alien species worldwide. Nat Commun 8:14435
Sheppard CS (2013) Potential spread of recently naturalised plants in New Zealand under climate change. Clim Change 117:919-931

Sheppard CS, Burns BR, Stanley MC (2016) Future-proofing weed management for the effects of climate change: is New Zealand underestimating the risk of increased plant invasions? N Z J Ecol 40:398-405

Suckling DM (2013) Benefits from biological control of weeds in New Zealand range from negligible to massive: a retrospective analysis. Biol Control 66:27-32

Suckling DM, Sforza RFH (2014) What magnitude are observed non-target impacts from weed biocontrol? PLoS ONE 9:e84847

Thomson GM (1922) The naturalisation of plants and animals in New Zealand. Cambridge University Press, Cambridge

Waikato Regional Council (2019) Waikato regional pest management plan annual report 2018/19. Waikato Regional Council Hamilton, New Zealand

Walker S, Wilson JB, Lee WG (2003) Recovery of short tussock and woody species guilds in ungrazed Festuca novae zelandiae short tussock grassland with fertiliser or irrigation. N Z J Ecol 27:179-189

Walker S, Comrie J, Head N et al (2016) Hawkweed invasion does not prevent indigenous non-forest vegetation recovery following grazing removal. N Z J Ecol 40:137-149

Webb CJ, Sykes WR, Garnock-Jones PJ (1988) Flora of New Zealand. Vol. IV. Naturalised pteridophytes, gymnosperms, dicotyledons. Botany Division DSIR, Christchurch

Williams PA (1992) Hakea sericea - seed production and role in succession in Golden Bay, Nelson. J R Soc N Z 22:307-320

Williams PA (1997) Ecology and management of invasive weeds. Conservation sciences publication 7. Department of Conservation, Wellington

Williams PA, Braithwaite $\mathrm{H}$ (2003) The future of weeds in Cantebury landscapes. Canterb Bot Soc 37:73-86

Williams PA, Buxton RP (1995) Aspects of the ecology of two species of Passiflora (Passiflora mollissima (Kunth) L. Bailey and Passiflora pinnatistipula Cav.) as weeds in South Island, New Zealand. N Z J Bot 33:315-323

Williams PA, Cameron EK (2006) Creating gardens: the diversity and progression of european plant introductions. In: Allen RB, Lee WG (eds) Biological invasions in New Zealand. Springer, Berlin, pp 33-47

Williams JA, West CJ (2000) Environmental weeds in Australia and New Zealand: issues and approaches to management. Austral Ecol 25:425-444

Williams PA, Popay I, Gatehouse HAW (2010) New Zealand biosecurity legislation and the naturalization of exotic weeds. Plant Prot Q 25:95-98

Wiser SK, Buxton RP, Clarkson BR et al (2013) New Zealand's naturally uncommon ecosystems. In: Dymond JR (ed) Ecosystem services in New Zealand-conditions and trends. Manaaki Whenua Press, Lincoln

Worsley K (1999) Pest plants and their control. In: Oates MR (ed) New Zealand plants and their story. Royal New Zealand Institute of Horticulture, Wellington, pp 29-32

Wotton DM, McAlpine KG (2013) Predicting native plant succession through woody weeds in New Zealand. DOC Research and Development Series 336 
Yamoah E, Gill GSC, Massey E (2013) Eradication programme for four noxious weeds in New Zealand. N Z Plant Prot 66:40-44

Zimdahl RL (2018) Fundamentals of weed science. Academic Press, London
Publisher's Note Springer Nature remains neutral with regard to jurisdictional claims in published maps and institutional affiliations. 